\begin{tabular}{|c|c|}
\hline Title & Evolution of the 2011 Tohoku Earthquake Tsunami on the Pacific Coast of Hokkaido \\
\hline Author(s) & W atanabe, Y asunori; Mitobe, Y uta; Saruwatari, A yumi; Y amada, Tomohito; Niida, Y asuo \\
\hline Citation & $\begin{array}{l}\text { Coastal Engineering Journal, 54(1), } 1250002 \\
\text { https://doi.org/10.1142/S0578563412500027 }\end{array}$ \\
\hline Issue Date & $2012-03$ \\
\hline Doc URL & http:/hdl.handle.net/2115/49122 \\
\hline Rights & $\begin{array}{l}\text { Electronic version of an article published as Coastal Engineering Journal, 54(1), 2012, 1250002, } \\
10.1142 / S 0578563412500027 \text { @ copyright W orld Scientific Publishing Company. } \\
\text { http:/www.worldscinet.com/cej/cej.shtml }\end{array}$ \\
\hline Type & article (author version) \\
\hline File Information & CEJ54-1_1250002.pdf \\
\hline
\end{tabular}

Instructions for use 


\title{
EVOLUTION OF THE 2011 TOHOKU EARTHQUAKE TSUNAMI ON THE PACIFIC COAST OF HOKKAIDO
}

\author{
YASUNORI WATANABE \\ School of Engineering, Hokkaido University \\ North 13 West 8, Sapporo, 060 8628, Japan \\ yasunori@eng.hokudai.ac.jp \\ YUTA MITOBE \\ School of Engineering, Hokkaido University \\ North 13 West 8, Sapporo, 060 8628, Japan \\ AYUMI SARUWATARI \\ School of Engineering, Hokkaido University \\ North 13 West 8, Sapporo, 060 8628, Japan \\ TOMOHITO YAMADA \\ School of Engineering, Hokkaido University \\ North 13 West 8, Sapporo, 060 8628, Japan \\ YASUO NIIDA \\ School of Engineering, Hokkaido University \\ North 13 West 8, Sapporo, 060 8628, Japan
}

Received (29 November 2011)

Accepted (31 January 2012)

\begin{abstract}
A numerical computation of the 2011 Tohoku earthquake tsunami was performed to identify fundamental features of the tsunami evolution along the coast of Hokkaido, Japan. Edge waves formed at multiple locations where the refracted tsunami focused, governing local surface oscillations and regional variations in tsunami height along the Pacific coast of Hokkaido. The computation reasonably reproduced the distribution of surveyed tsunami height as well as the time records of surface elevation recorded at ports in Hokkaido. The major features of the frequency spectrum for the 2011 Tohoku tsunami were identical to those for the 2003 Tokachi-oki earthquake tsunami; inherent local properties of surface oscillation caused by the passage of edge waves existed, determined by the local bathymetry.
\end{abstract}

Keywords: 2011 Tohoku earthquake tsunami; Hokkaido; Edge wave. 


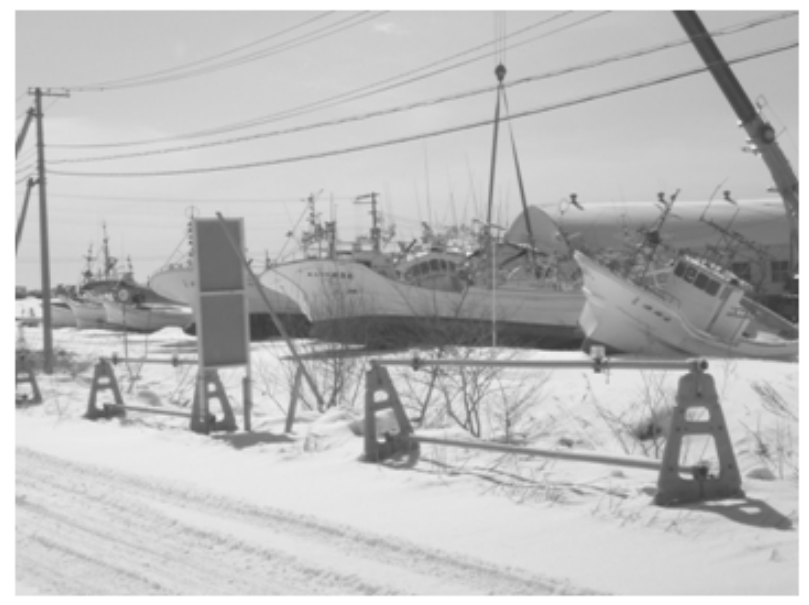

Fig. 1. Many fishing boats were brought ashore by the tsunami at Otsu harbor, which is located in the middle of Area III in Fig. 4.

\section{Introduction}

Hokkaido, the northernmost island of Japan, is located between the boundaries of the Eurasian, North American, and Pacific plates and has been often affected by tsunamis. Examples include the Tokachi-oki earthquake tsunamis in 1952, 1968, and 2003, the Hokkaido Nansei-oki tsunami in 1993, and the Sanriku-oki tsunami in 1933. The 2011 Tohoku earthquake tsunami arrived at Hokkaido one hour after the earthquake occurred at 14:46 on 11 March 2011 (see overall features of the tsunami in Mori et al. 2012). A consecutive onrush with significant inundation, especially along Pacific coastal areas of Hokkaido, repeated over one day from the onset, causing one death and $\$ 300$ million damage to ports and harbors, cultural resources and facilities, buildings, fishing boats, and vehicles (see Fig. 1). This paper focuses on the evolution of the tsunami along the Hokkaido coast with the aim of understanding local influences. To this end, a tsunami height survey along the Pacific coast of Hokkaido and a tsunami computer simulation were used. The regional distribution of the maximum tsunami height and time-varying features of the surface elevation are discussed through comparison of surveyed and computed results.

This paper is organized as follows. The tsunami survey and overall features of tsunami heights along the Pacific coast of Hokkaido are described in section 2. Section 3 presents the computational method and procedures. In section 4, major features of the tsunami evolution due to edge waves that emerged along the Hokkaido coast are discussed in terms of the regional properties of the measured and computed tsunami heights, as well as in comparison to the 2003 Tokachi-oki earthquake tsunami. Section 5 summarizes the results. 


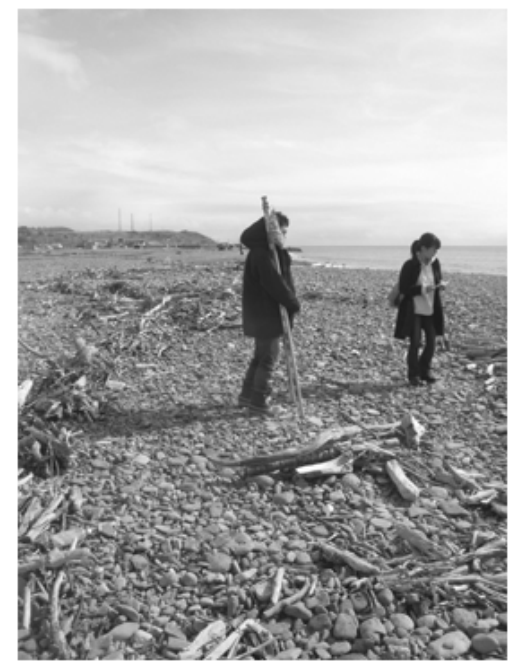

Fig. 2. Debris on the Samani coast near the east end of Area II in Fig. 4.

\section{Tsunami Height Survey}

A survey of tsunami inundation and run-up height on the Pacific coast of Hokkaido was conducted from 15 to 18 March 2011. The vertical levels of seawater marks on buildings and shore debris were measured by a level and laser distance meter (see Fig. 2). These tsunami heights were corrected based on tide levels at the time when the maximum tsunami was expected to arrive at the sites, following the method of Mori et al. (2011). Tide records at eight ports in Hokkaido, provided by the Hokkaido Development Bureau, were used to interpret frequency features for the successive tsunami arrivals, as well as for comparison with the computed surface elevation.

The distribution of the measured inundation and run-up heights, and the maximum tide level at the ports along the Hokkaido coast (shown in Fig. 3) were as follows: heights of 1 to $3 \mathrm{~m}$ in the southwest (see Area I in Fig. 4) and 2 to $5 \mathrm{~m}$ in Area II, run-up heights from $3 \mathrm{~m}$ to slightly less than $6 \mathrm{~m}$ in area III, and 2 to 4 $\mathrm{m}$ of inundation along the east coast (Area IV). The maximum inundation height of $4.68 \mathrm{~m}$ was observed along the rocky coast near Cape Erimo (see the east end of Area II in Fig. 4). A maximum run-up height of $5.9 \mathrm{~m}$ occurred on a steep sandy beach in the middle of Area III (see also Fig. 13).

The local variations in the surveyed tsunami height will be explained in terms of the evolution of the computed tsunami in $\S 4$.

\section{Computation}

While the domain for tsunami computation needs to cover a wide ocean area, high spatial resolution is also required for local bathymetry and landform modeling to reproduce both local flows at coastal areas and wave run-up. Steep tsunami wave fronts 


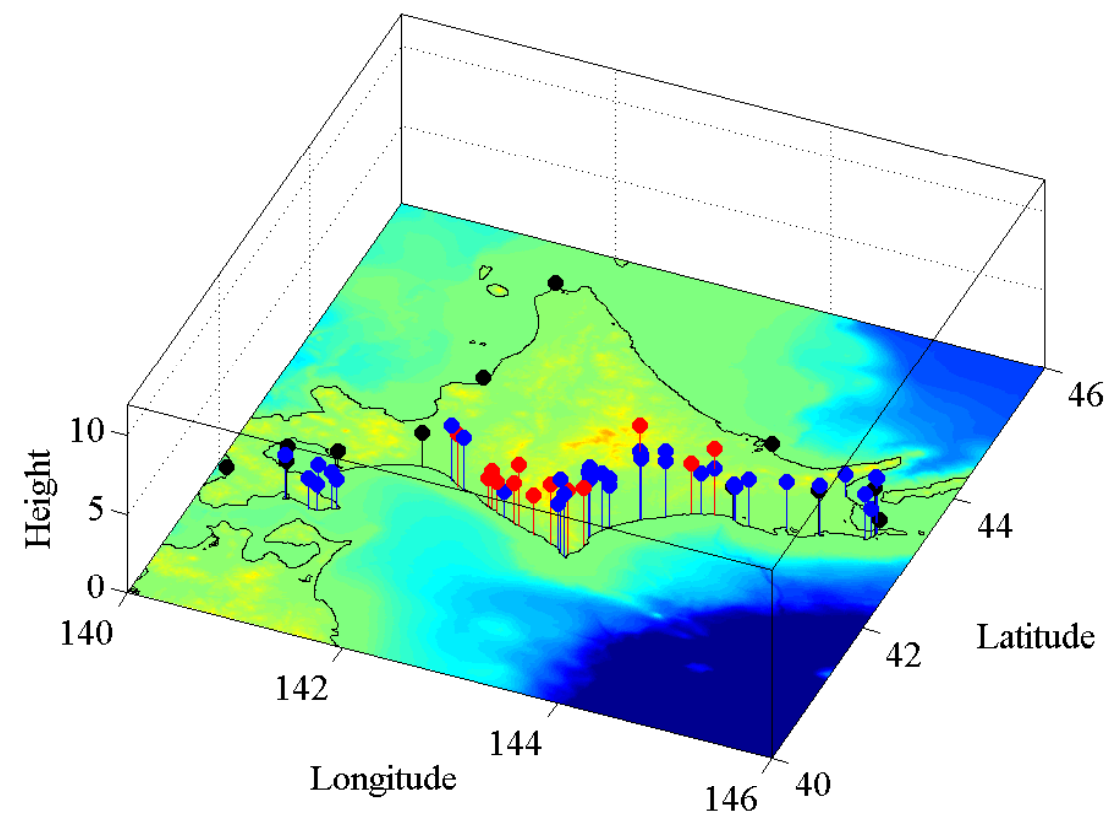

Fig. 3. Distribution of the surveyed tsunami heights; run-up height (red), inundation height (blue), and maximum surface level estimated from the tide record at a port (black).

must also be sufficiently resolved to preserve the nonlinear wave shape throughout the propagation, to accurately determine the tsunami height along the shore. However, tsunami computation on highly resolved fine grids for the entire ocean domain is slow and impractical. Adaptive mesh refinement (AMR) is one possible technique to support both high-resolution and high-efficiency computation. It is based on dynamic operation of the resolution level. In the AMR environment, tsunami computation can be performed over ten times faster than conventional computation at the same resolution on a single CPU. Further acceleration can be expected in a parallel computing environment (Watanabe et al. 2011).

\subsection{Adaptive Mesh Refinement}

In the AMR environment, a computational domain is composed by creating blocks containing computing grids to solve a discretized equation system (100 grids were used for each block in this study). The block size quarters with each increase in the refinement level in a quad-tree block structure (see Fig. 5). Hence the resolution increases four times for one refinement level. The spatial resolution of surface waves can be dynamically controlled in an AMR environment. When local gradients of surface displacement exceed a certain refinement threshold, the computational block 


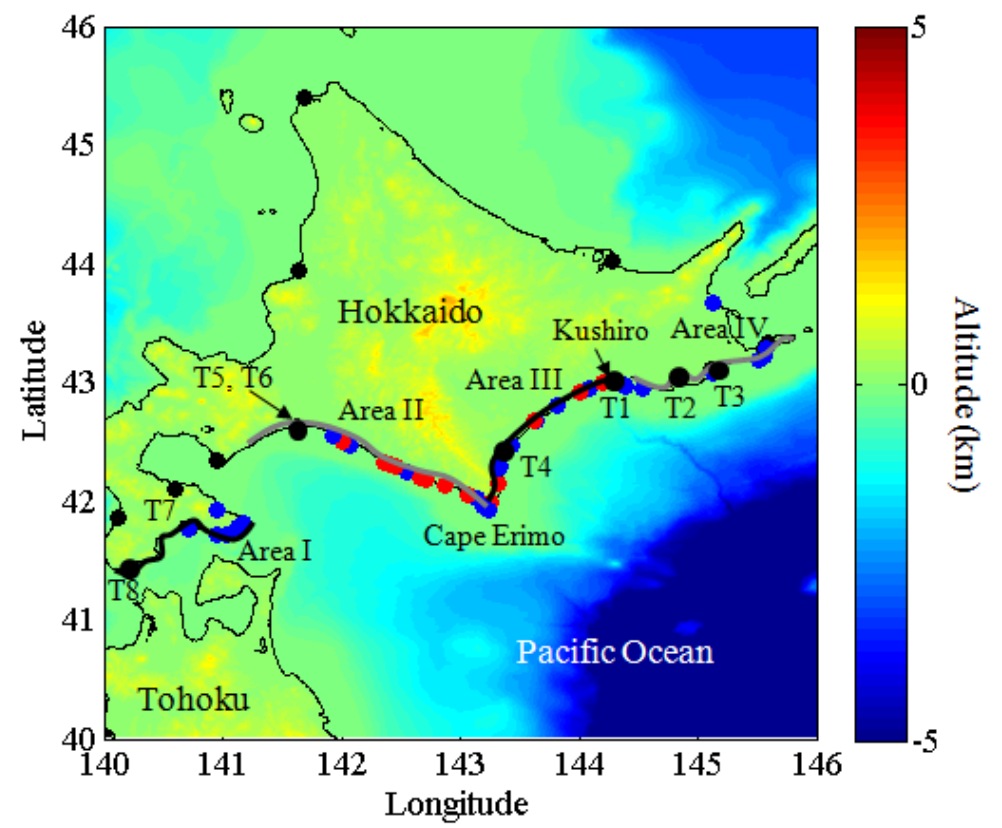

Fig. 4. Locations of the survey sites corresponding to Fig. 3.

is refined to resolve changes in the surface shapes, whereas if the surface gradients fall below another threshold the block is de-refined to save computing cost.

In this way, the steep wave front and local wave deformation at coastal areas can be highly resolved, while low resolution computation on coarse grids is performed in quiescent regions before wave arrival or after wave passage. Tsunami evolution can be efficiently computed at the resolution and computational cost required by the user when sufficient maximum and minimum refinement levels are provided.

The AMR library PARAMESH was introduced in the current nonlinear tsunami computation (for other applications of PARAMESH, see MacNeice et al. 2000 and Pancheshnyi et al. 2008).

\subsection{Numerical Procedures}

This study used the nonlinear long wave equation and depth-integrated continuity equation

$$
\begin{gathered}
\frac{\partial \boldsymbol{u}}{\partial t}+(\boldsymbol{u} \boldsymbol{\nabla}) \boldsymbol{u}=-g \boldsymbol{\nabla} \eta+\nu_{h} \boldsymbol{\nabla}^{2} \boldsymbol{u}+\frac{f}{\eta+h}|\boldsymbol{u}| \boldsymbol{u}, \\
\frac{\partial \eta}{\partial t}+\boldsymbol{\nabla} \cdot(\boldsymbol{u}(h+\eta))=0
\end{gathered}
$$




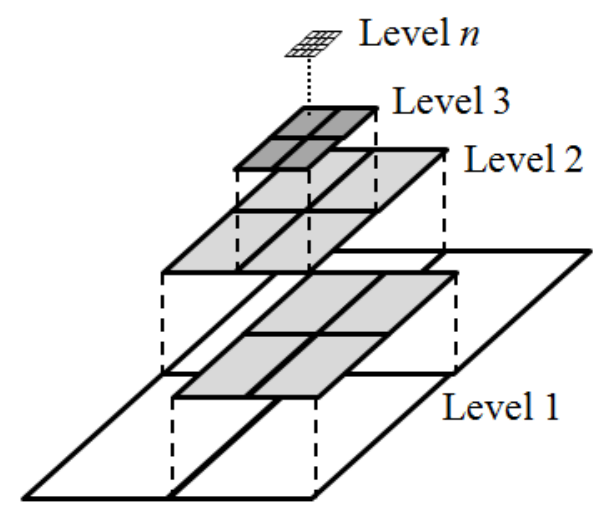

Fig. 5. Schematic representation of multi-level block refinements based on a quad-tree structure in the AMR environment.

where the depth-averaged velocity $\boldsymbol{u}=\frac{1}{h+\eta} \int_{-h}^{\eta} \boldsymbol{u}^{\prime} d z$, and $\boldsymbol{u}^{\prime}, \eta, h, \nu_{h}$ and $f$ are the local fluid velocity, surface displacement, water depth, laminar diffusion coefficient and friction factor, respectively. Lynett, Wu and Liu (2002) examined bottom friction for the depth-integrated wave equation to reproduce wave run-up on a smooth sloping bed. They found the bottom friction is insensitive to the run-up height when relative wave height $(a / h)$ is sufficiently small (such as $a / h \leq 0.01$, where $a$ is the wave amplitude). The friction $f=5 \times 10^{-3}$ showed the best agreement with experiments for larger waves at $a / h=0.3$. The identical friction factor was also used in the current computation. The Coriolis effect was neglected in this computation. Using a so-called multiple fractional step method, the finite difference form of equation (1) was decomposed into three discrete forms (Kim and Moin 1985). The momentum equations for a pressure gradient, diffusion and advection terms were separately computed in three fractional levels as

$$
\begin{gathered}
\boldsymbol{u}^{*}=\boldsymbol{u}^{n}-\Delta t g \boldsymbol{\nabla} \eta^{n} \\
\boldsymbol{u}^{* *}=\boldsymbol{u}^{*}+\Delta t\left(\nu_{h} \boldsymbol{\nabla}^{2} \boldsymbol{u}^{*}+\frac{f}{\eta+h}\left|\boldsymbol{u}^{*}\right| \boldsymbol{u}^{*}\right), \\
\frac{D \boldsymbol{u}^{n+1}}{D t}=\frac{\partial \boldsymbol{u}^{n+1}}{\partial t}+\left(\boldsymbol{u}^{* *} \boldsymbol{\nabla}\right) \boldsymbol{u}^{n+1}=0
\end{gathered}
$$

where the superscript $n$ indicates a time step number, and * indicates an intermediate time step between $n$ and $n+1$. The discrete forms of equation (2) in the fractional levels are also described by

$$
\begin{gathered}
\eta^{n+1}=\eta^{n}-\Delta t\left(\boldsymbol{\nabla} \cdot\left(\boldsymbol{u}^{* *} h\right)-\eta \boldsymbol{\nabla} \cdot \boldsymbol{u}^{* *}\right), \\
\frac{D \boldsymbol{\eta}^{n+1}}{D t}=\frac{\partial \eta^{n+1}}{\partial t}+\left(\boldsymbol{u}^{* *} \boldsymbol{\nabla}\right) \eta^{n+1}=0 .
\end{gathered}
$$




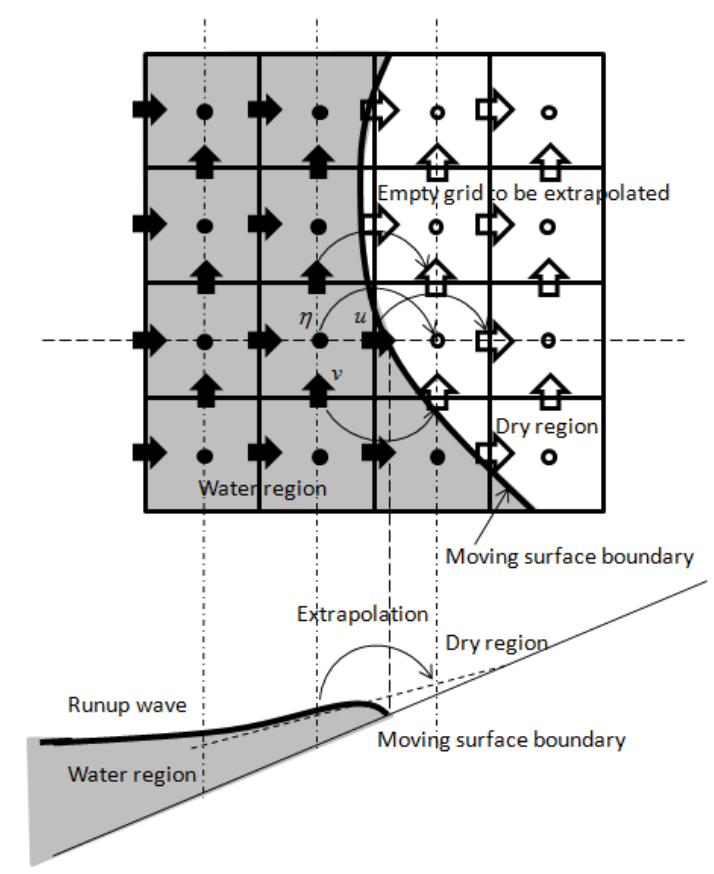

Fig. 6. Extrapolation procedure of fluid velocity and surface displacement into empty staggered grids on dry bed.

The mean velocity and surface elevation for the linear equations (3), (4), and (6) were updated using a predictor-corrector method. The advection equations (5) and (7) were computed using a semi-Lagrangian scheme, the constrained interpolation profile (CIP) method (see Watanabe et al. 2005 for details of the numerical methods), which gives nonlinear inertial effects to be significant in shoaling and run-up processes.

In flows with moving surface boundaries, fluid velocity, surface displacement and their gradients need to be extrapolated into empty grid cells outside the water region (dry region) for solving equations (5) and (7) on fixed grid system. Watanabe, Saruwatari and Ingram (2008) presented a numerical extrapolation technique for computing three-dmesnional free-surface flows. In this method, a so-called ghost velocity is extrapolated to fulfill the dynamic boundary condition at the free-surface. Lynett, Wu and Liu (2002) developed a moving boundary technique based on linear extrapolation into the dry region for computing the wave runu-up by depthintegrated equations. In the current computation, zero gradient of the first derivative is assumed across the surface boundary as a simple approximation of local steady-state of acceleration of the wave front (see Fig. 6); that is, identical $\boldsymbol{\nabla} \boldsymbol{u}$ and $\nabla \eta$ adjacent to the boundary in the water region are extrapolated into the empty grids in the dry region. The ghost fluid velocity and surface displacement in the empty grids are determined via the first order approximation of Taylor series. It 
should be noted that this approximation of the boundary displacement might be inaccurate for run-up flows on highly curved ground form. Because the advection of the momentum and surface elevation throughout the water region can be directly solved through the velocity extrapolations in a Lagrangian way by the CIP method, local inundation process during the run-up can be explicitly computed.

In the AMR environment, all variables at boundary grids were interpolated from the adjacent grids within the neighboring block to be shared between the blocks with different refinement levels. In this computation, second-order polynomials were used for the interpolation. This approximation process was identical to the finite difference approximation; hence possible numerical errors associated with transfer of variables between blocks were minimized.

\subsection{Numerical Conditions}

The AMR tsunami computations were performed for the 2011 Tohoku and 2003 Tokachi-oki earthquake tsunamis. A digital bathymetry dataset with 30 -second resolution (grid spacing of about $500 \mathrm{~m}$ ), provided by the Japan Oceanographic Data Center, was used in this computation. As an initial condition, surface elevation identical to the coseismic uplift of the fault model proposed by the Geospatial Information Authority of Japan was given at the seismic areas for both earthquakes (see phase (a) of Fig. 7). A wave attenuation region with high prescribed bottom friction was installed on the inner sides of the open boundaries. There, zero normal gradient velocity was imposed as a boundary condition.

\section{Results}

The observed tsunami heights were interpreted on the basis of the computed results to investigate how the tsunami travelled to and developed on the coast of Hokkaido.

\subsection{Tsunami Propagation}

The computed surface elevation after the earthquake and the computing blocks to resolve the waves are shown in Fig. 7. Because the adaptive mesh dynamically resolved the tsunami with high gradients of surface elevation, sharp nonlinear wave shapes that propagated radically from the source region could be conserved on fine quad-tree grids. Near-shore regions were also found in phase (c) of Fig. 7 to be covered by the finest computing blocks at the maximum refinement level. This ensured that significant variations in the shoaling waves, depending on local water depths and landforms, were reasonably computed at an identical resolution to the bathymetry data $(500 \mathrm{~m})$. The computing blocks were merged into coarser blocks in the region where the wave had passed to accelerate the computation (see the initial seismic area for phase (c) of Fig. 7).

The sequential locations of the computed tsunami wave front every 15 minutes are shown in Fig. 8. The tsunami first reached the middle of the Pacific coast of 

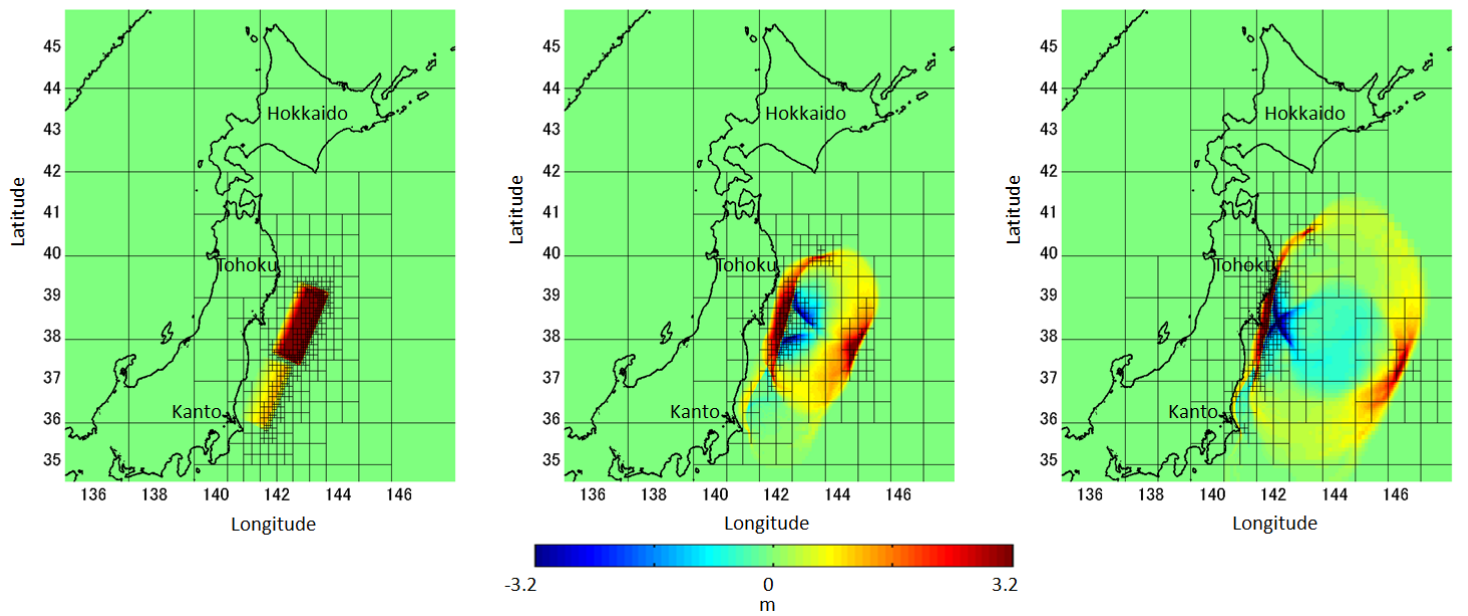

Fig. 7. Surface elevation at 34 s (a), 605 s (b), and 1197 s (c) from the earthquake.

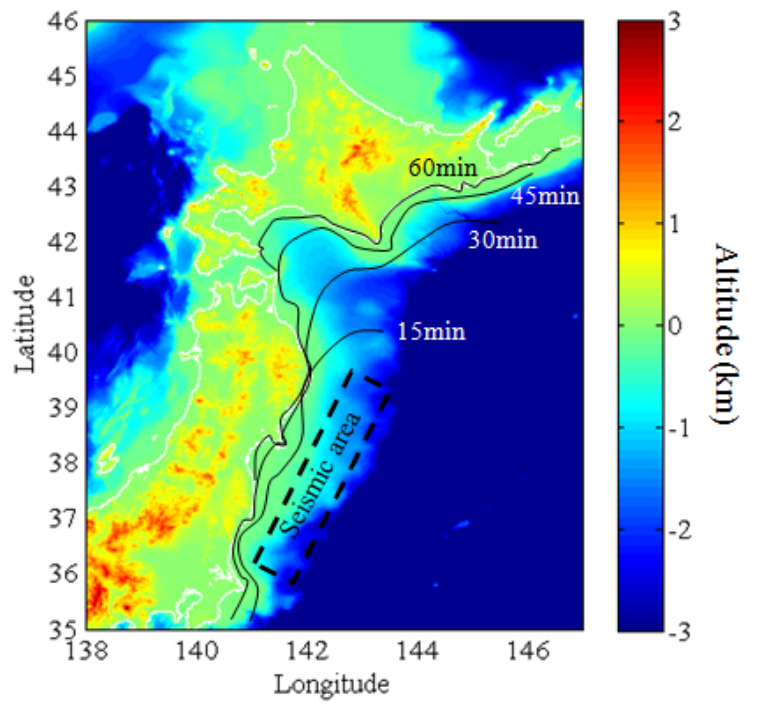

Fig. 8. Sequential locations of the tsunami wave front during the propagation of the 2011 Tohoku tsunami.

Tohoku 15 minutes after the earthquake. It arrived at the Pacific coast of Hokkaido (Areas II, III and IV) after 60 minutes and at Area I after 70 to 90 minutes. It was found that the tsunami was refracted off Cape Erimo, located between Areas II and III, and off northernmost Tohoku (see area locations in Fig. 4). 

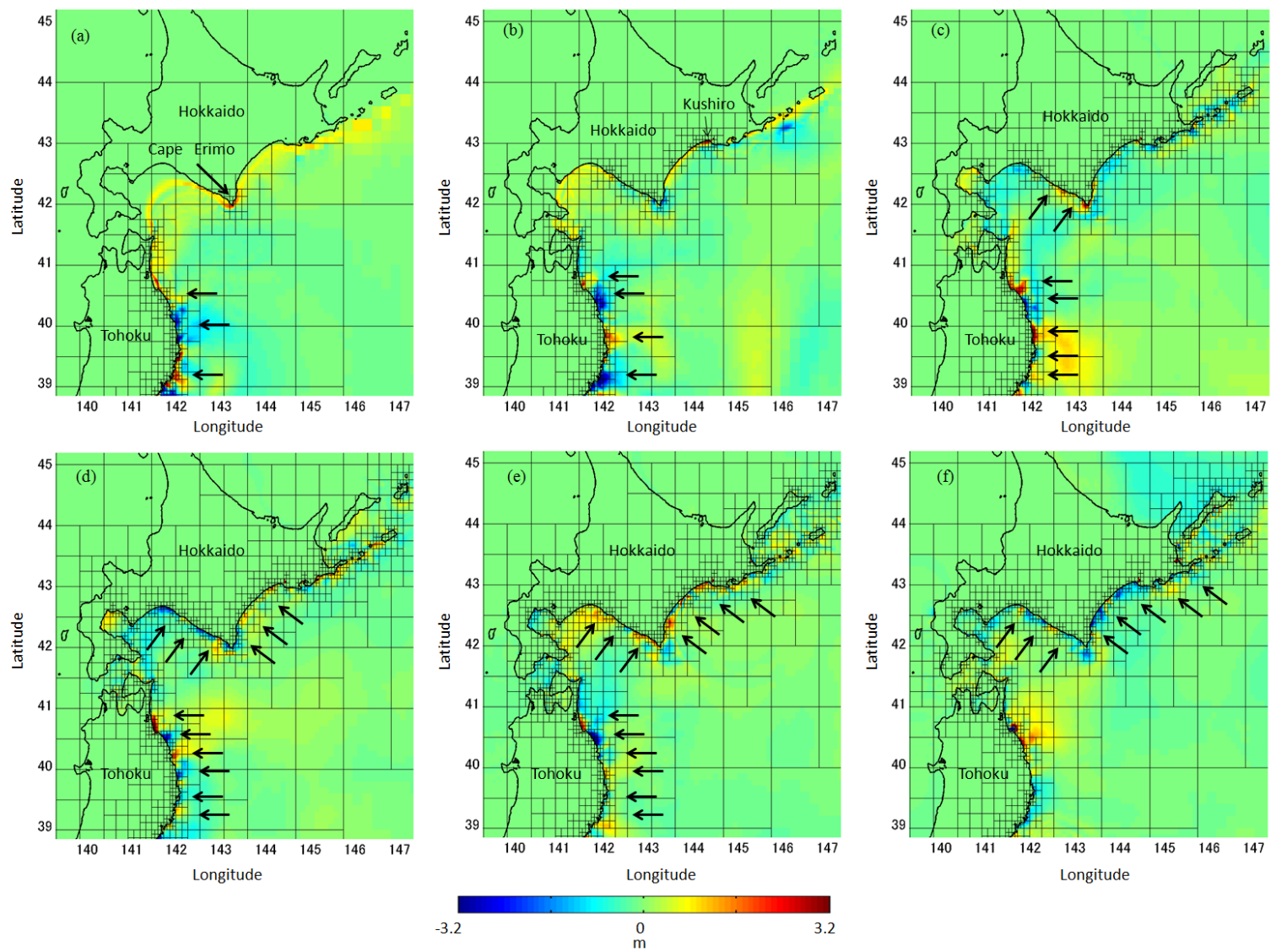

Fig. 9. Surface elevation at $3216 \mathrm{~s}$ (a), $4251 \mathrm{~s}$ (b), $6580 \mathrm{~s}$ (c), $7619 \mathrm{~s}$ (d), $9648 \mathrm{~s}$ (e), and 11,836 s after the earthquake. Crests and trounghs of the edge waves are indicated by arrows.

\subsection{Tsunami Evolution on the Pacific Coast of Hokkaido}

The tsunami refracted off Cape Erimo (see the wave front at 30 and 45 minutes after the earthquake in Fig. 8) focused at the cape, resulting in significantly amplified wave height and an uneven surface along the coasts of Areas II and III (see the phase (a) in Fig. 9). This supported the fact that the maximum inundation height in Hokkaido was achieved at Cape Erimo (see Fig. 3). The surface gradient that appeared around the cape induced coastal trapped waves travelling both west and east alongshore (so-called edge waves), resulting in typical alongshore surface undulations with wavelengths of $50-80 \mathrm{~km}$. These were positive and negative surface elevations that were aligned to the coast (see arrows in Areas II and III at phases (c) to (f) of Fig. 9). Long-term surface oscillations were then observed to successively form near Cape Erimo, following the edge waves. In addition, another wave amplification that occurred near Kushiro in phase (b) also induced edge waves spreading 

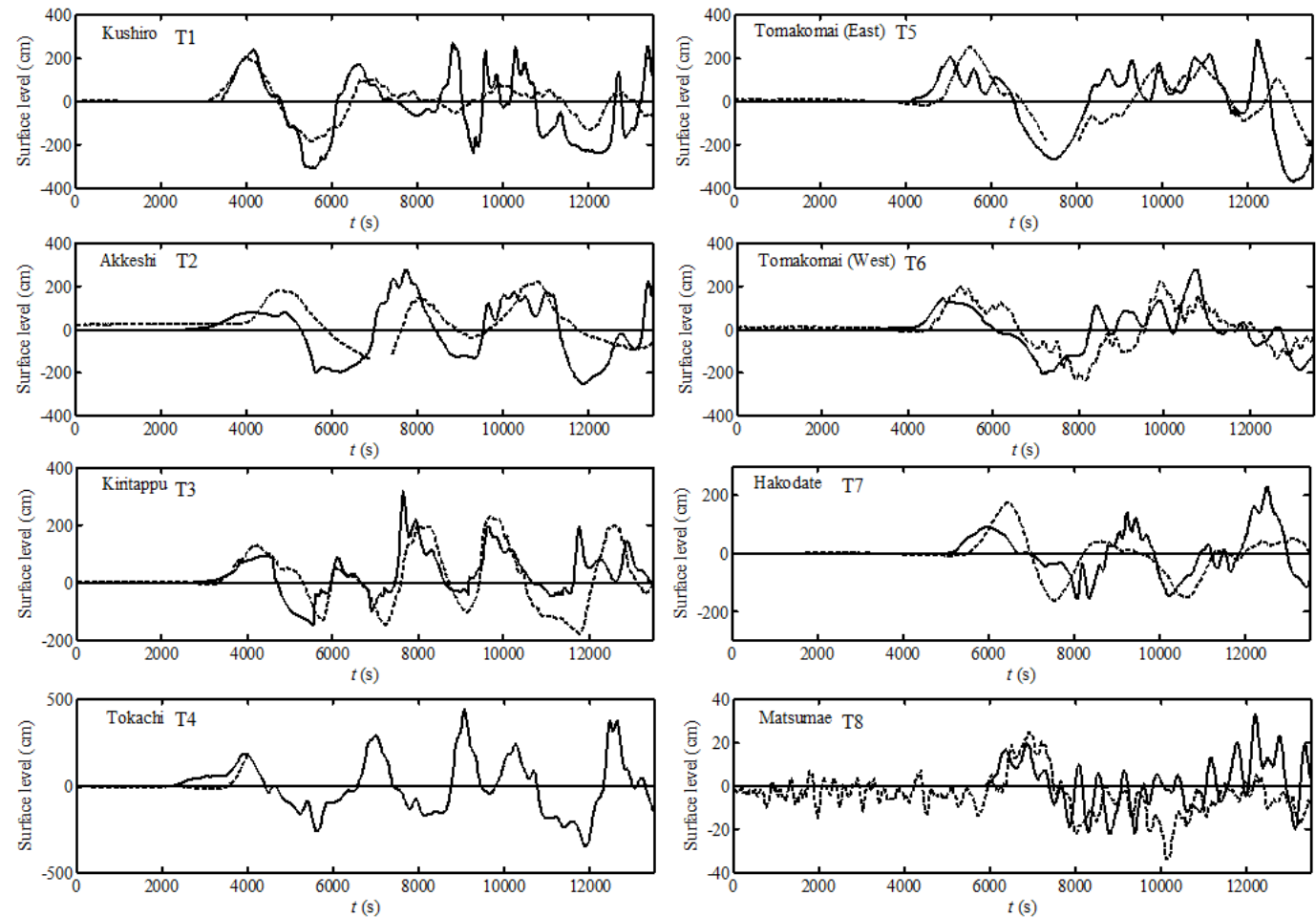

Fig. 10. Time records of the computed (solid line) and observed (broken line) surface elevation of the tsunami at Kushiro (T1), Akkeshi (T2), Kiritappu (T3), Tokachi (T4), Tomakomai east and west (T5, T6), Hakodate (T7) and Matsumae (T8) ports (see the site locations in Fig. 4). The data represent the deviation from astronomical tide levels at each port.

in both directions along the shore in Areas III and IV. The superposition of the edge waves that were triggered at multiple locations determined the local maxima of the tsunami heights, resulting in local variations along the shoreline as seen in the survey data (see Fig. 3 and also Fig. 13). These alongshore waves slowly spread along the whole coast of Hokkaido, causing consecutive local surface oscillations for a long time, as observed in the tide records (see Fig. 10). Identical evolution of the edge waves was also observed along the Hokkaido coast in the 2003 Tokachi-oki earthquake tsunami, as reported in Kawata et al. (2004), which will be discussed later. On the Pacific coast of Tohoku, edge waves were also observed to typically propagate northward, indicating that large-scale edge waves with wavelength of 80 - $130 \mathrm{~km}$ also affected the tsunami evolution there (see arrows on the Tohoku coast in Fig. 9).

Typical surface oscillations owing to the passage of the alongshore edge waves were found in the time records of the observed and computed surface elevations at the observation sites of Kushiro (T1), Akkeshi (T2), Kiritappu (T3), Tokachi (T4), 
Tomakomai east and west (T5, T6), Hakodate (T7), and Matsumae (T8) ports (see Fig. 10 and also the sites in Fig. 4). Agreements among the major features of the computed and observed long-term oscillations indicated the reliability of the simulations. Further improvement of the accuracy is expected if higher resolution bathymetry data become available.

A dispersion relation of edge waves induced on a straight and long beach with constant slope $(s)$ is given by

$$
\frac{\sigma^{2}}{2 k s g}=n+\frac{1}{2}, \quad n=0,1,2, \ldots
$$

where $\sigma$ is the angular frequency, $k$ is the wave number, and $n$ is the mode number (Mei 1983, González et al. 1995). The wavelength of the 0th mode edge wave for the dominant frequencies of $3-4 \times 10^{-4} \mathrm{~Hz}$ of the surface oscillations at Kushiro port (see Fig. 10 and also Fig. 16) is estimated to be 43 to $76 \mathrm{~km}$, which coinsides with those identified from the computed waves (see Fig. 9). Any higher mode wave with longer wavelength was not observed in the computed results. Fujima et al. (2000) characterized typical behaviors of the edge waves in terms of the mode dependencies. They found the 0th mode wave features that a regular wave train is formed to propagate alongshore for long time and that the tsunami height is locally amplified by resonance, which is consistent with major features observed in the current computed tsunami. Therefore, we conclude the costal-trapped, 0th mode edge waves governed the current tsunami evolution on the Pacific coast of Hokkaido.

\subsection{Maximum Tsunami Heights}

The distribution of the computed maximum tsunami heights at the grid points where the water depths were shallower than $10 \mathrm{~m}$ during total computed time of 4 hours after the earthquake is shown in Fig. 11. Because the maximum tsunami height was achieved after a lapse of 6 hours from the earthquake at Hakodate, Kushiro, and Kiritappu ports, according to the tide records, there might be local discrepancies from the surveyed results shown in Fig. 3. Although there were regional variations in the tsunami height along the coastline, relatively high elevations were achieved in the region where significant wave run-up was observed (see also Fig. 12).

The regional maxima of the computed tsunami heights are compared with the surveyed heights in Fig. 13. Although computed wave heights were overestimated in several locations in Areas II and III, the overall features of the regional variations of the tsunami heights were consistent with the survey results, supporting our conclusion that the regional properties of tsunami heights along the Hokkaido coast were determined by the superposition of the edge waves, discussed in the previous section. More accurate computation can be expected if higher resolution bathymetry data become available. 


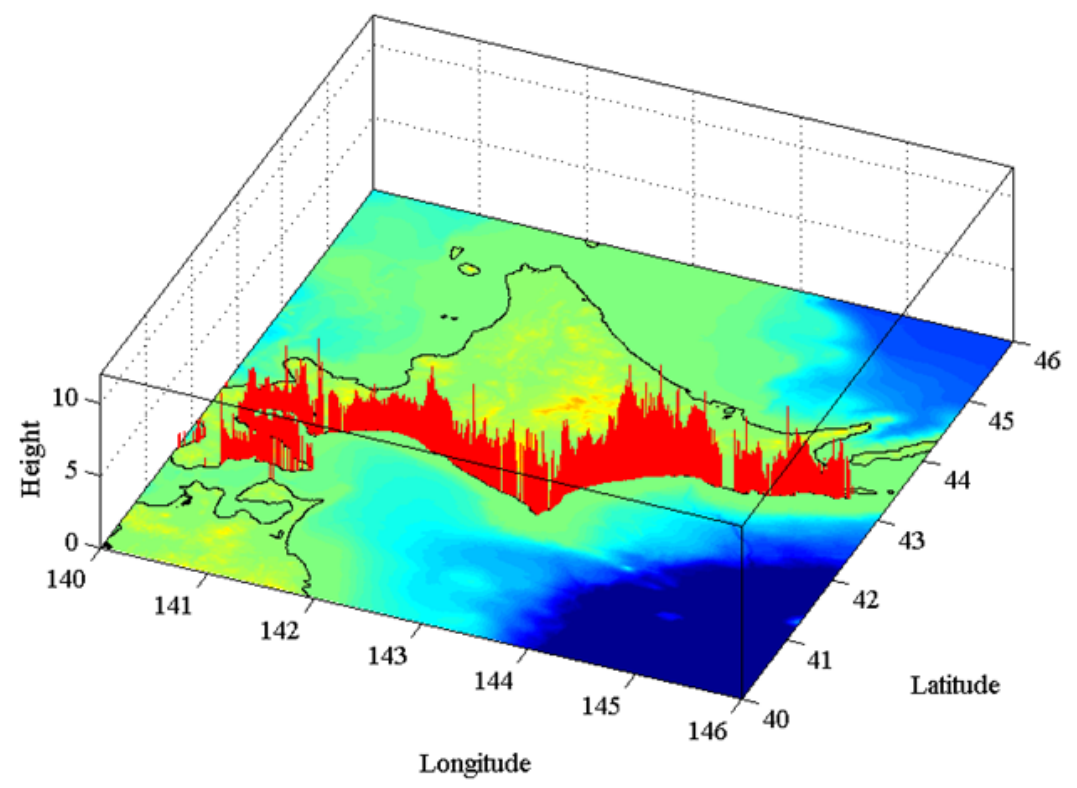

Fig. 11. Distribution of the computed tsunami height along the coast of Hokkaido.

\subsection{Comparison with the 2003 Tokachi-oki Earthquake Tsunami}

The 2003 Tokachi-oki earthquake tsunami occurred by reverse fault displacement off Tokachi Bay (Area III) during the plate-boundary earthquake of magnitude 8.0 on 26 September 2003. The rupture length was about $90 \mathrm{~km}$ and the slip distance was about $5 \mathrm{~m}$. These values were much smaller than those of the 2011 Tohoku earthquake tsunami (compare seismic areas in Fig. 8 and Fig. 14). Tsunami heights of 1-3 m, also smaller than those in the 2011 Tohoku tsunami, were also observed along the Pacific coast of Hokkaido. This section discusses analogies in the evolutions of these two tsunamis along the coast of Hokkaido.

The radically spreading wave front was initially amplified in a nearshore region of Area III (see phase (a) of Fig. 15). Then, local surface variations in wavelength of about 50-80 km were observed along the coastline (see phases (b) and (c)). In other words, identical 0th mode edge waves to those discussed in $\S 4.2$ were produced in the 2003 Tokachi-oki tsunami. Another analogous feature was that successive edge waves repeatedly formed off Cape Erimo, which was also pointed by Kawata et al. (2004) and Watanabe et al. (2011).

Imai et al. (2009) characterized long-term surface oscillations owing to self seiche, edge waves and harbor resonance in the 1944 Showa Towankai Earthquake tsunami. Frequency properties of the surface elevations in the both tsunamis are also discussed bellow. 


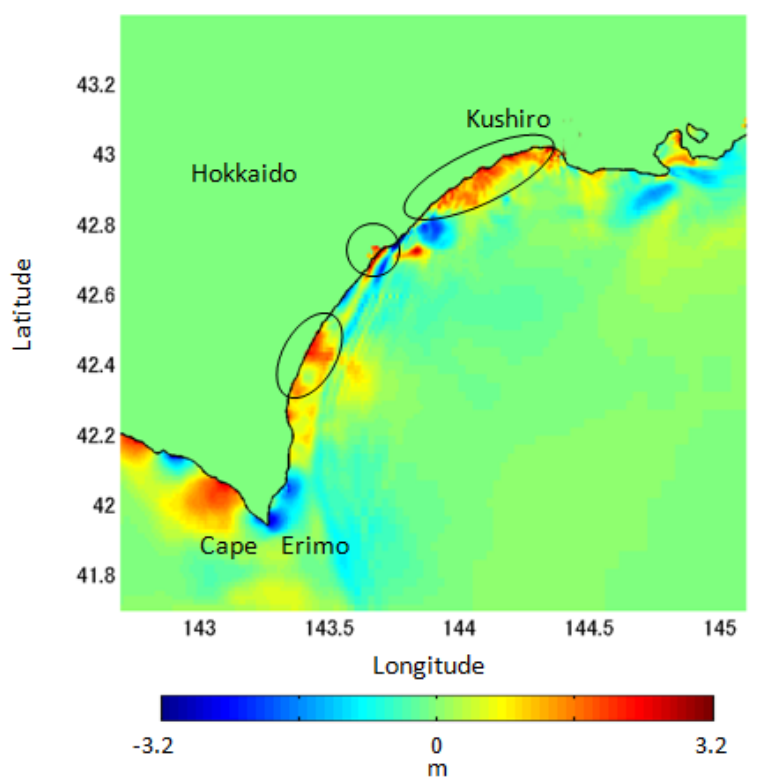

Fig. 12. Surface elevation and run-up regions (circled) at 10,048 s after the earthquake.

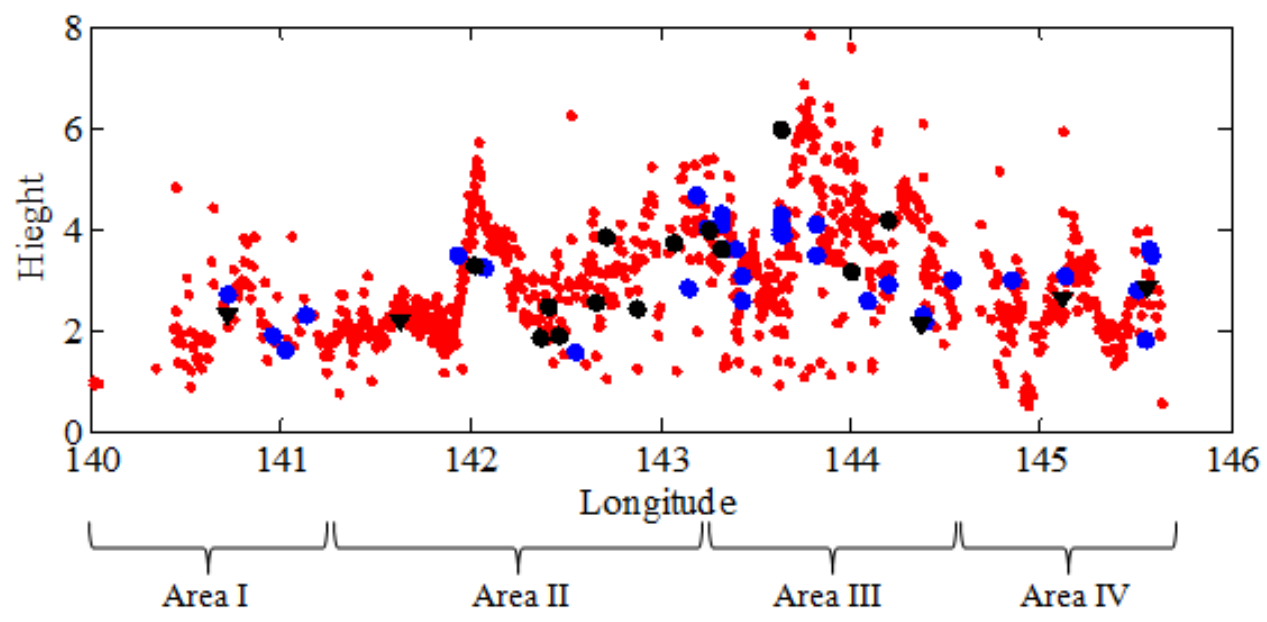

Fig. 13. Comparison of the regional maxima of the computed tsunami height (red dot) the surveyed inundation (blue circle) and run-up (black circle) heights, and the maximum height estimated from tide records at the studied ports (black triangle). See also distributions of the heights in Fig. 3 and Fig. 11. 


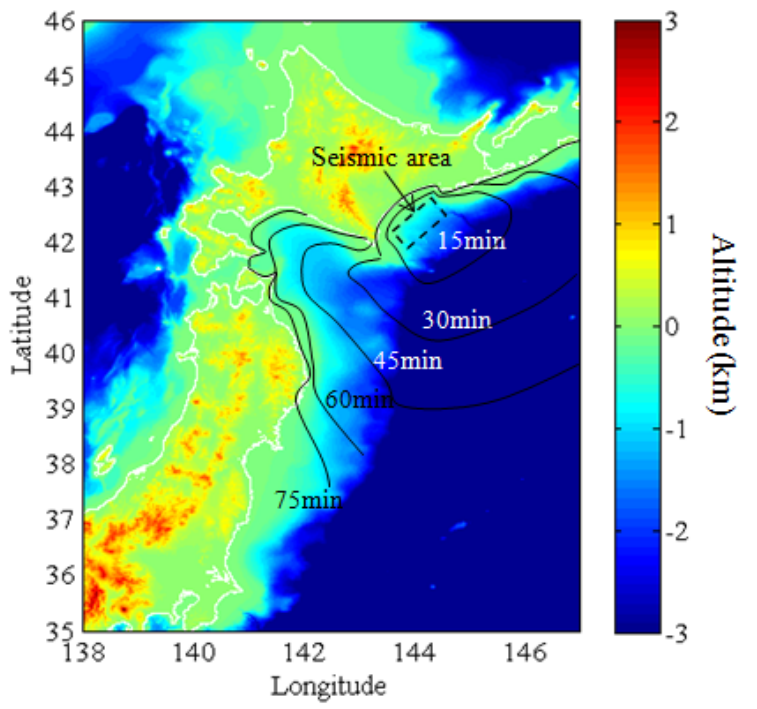

Fig. 14. Sequential locations of the tsunami wave front during propagation of the 2003 Tokachi-oki tsunami.

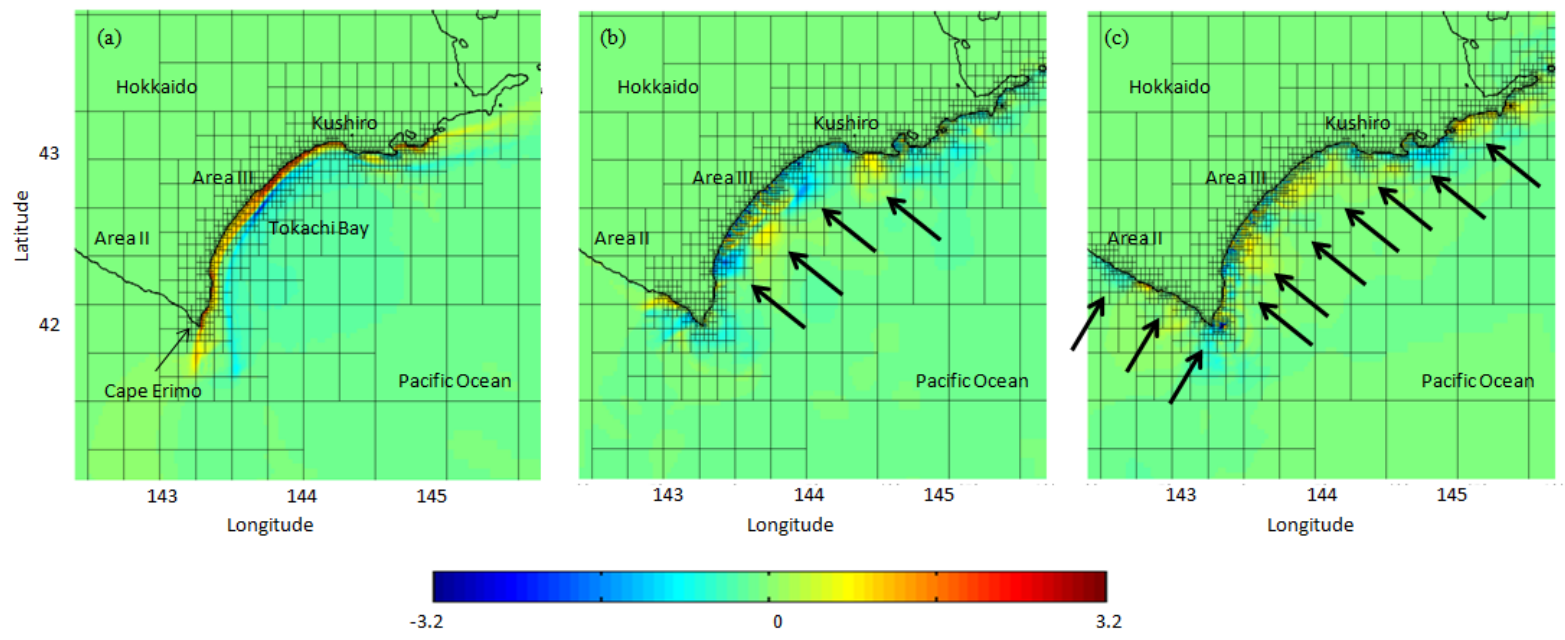

Fig. 15. Surface elevation at $1852 \mathrm{~s}$ (a), $3305 \mathrm{~s}$ (b), and $4868 \mathrm{~s}$ (c) after the 2003 Tokachi-oki earthquake. Crests and trounghs of the edge waves are indicated by arrows.

The frequency spectra of the tide records for both the 2011 Tohoku and 2003 Tokachi-oki tsunamis at Kushiro (T1) and Tomakomai west (T6) ports are compared in Fig. 16. The harbor resonance frequencies, $f \geq 3 \times 10^{3}$ for Kushiro and $f \geq$ 


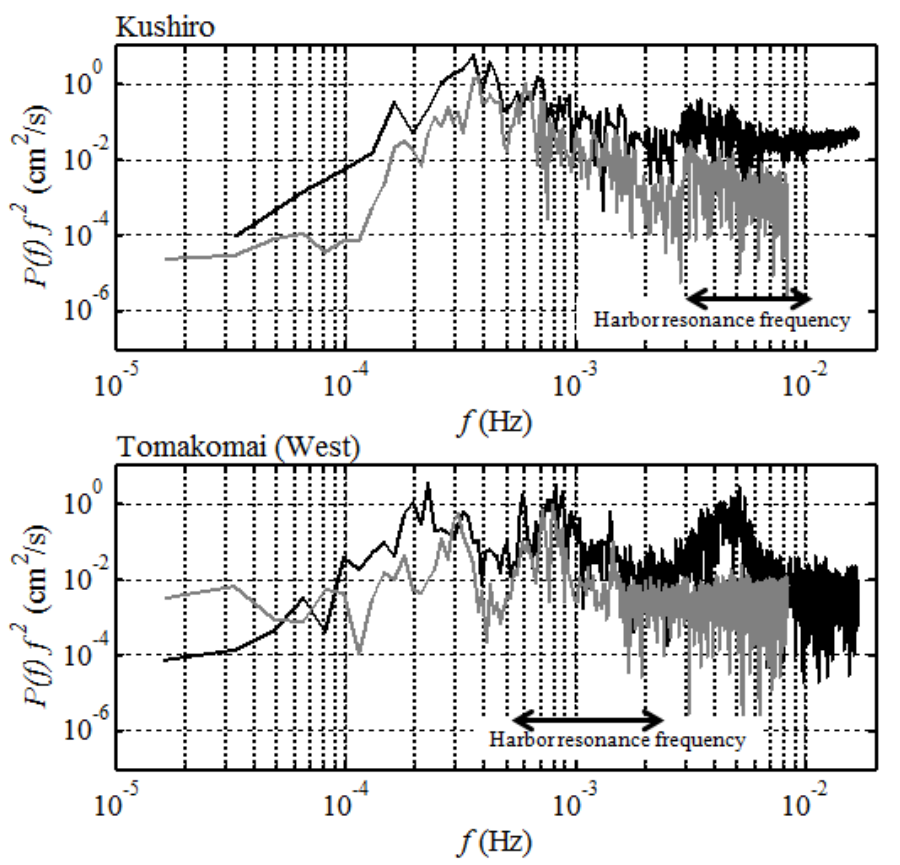

Fig. 16. Frequency spectra of the tide records at Kushiro (T1, top) and Tomakomai west (T6, bottom) ports during the 2001 Tohoku (black line) and 2003 Tokachi-oki (gray line) tsunamis.

$6 \times 10^{3}$ for Tomakomai have been identified (see resonance frequency ranges indicated by arrows in Fig. 16). Although the total energy density for the former energetic tsunami was higher than that for the latter, analogous spectrum shapes at low frequencies $\left(<2 \times 10^{-3} \mathrm{~Hz}\right)$ were found for the two tsunamis at both ports. This suggests that there was a local inherent statistical feature of successive tsunami oscillations. Major spectrum peaks, associated with the edge wave, also appeared at identical frequencies in ranges lower than the harbor resonance frequencies for both tsunamis: $4 \times 10^{-4}$ for Kushiro port (corresponding to 42 wave period), and $3 \times 10^{-4} \mathrm{~Hz}$ for Tomakomai port (54 minute wave period), which coinsides with the frequencies for the 0 th mode edge wave as already discussed in $\S 4.2$. This indicated that the frequency properties of the surface oscillations owing to passage of the edge waves were determined by local bathymetry and were independent of the initial magnitude of the tsunami.

\section{Conclusions}

A numerical computation of the 2011 Tohoku earthquake tsunami was performed to identify the fundamental features of tsunami evolution along the coast of Hokkaido. 
The refracted tsunami amplified off Cape Erimo and Kushiro induced successive periods of edge wave formation. These coastal trapped edge waves, which have 0th mode of alongshore oscillation, then propagated along the coastline. The superposition of edge waves formed at multiple locations resulted in alongshore variations in the maximum tsunami heights. The surveyed tsunami heights and tide records at ports on the Pacific coast of Hokkaido, which were reasonably reproduced in the computation, were supported by the computed edge waves evolving along the coast. A comparison between the 2011 Tohoku and 2003 Tokachi-oki tsunamis also showed that the fundamental properties of the surface oscillations due to 0th mode edge wave passage depended on local bathymetry and hence were identical for both tsunamis.

\section{Acknowledgments}

Some of the surveyed tsunami heights were provided by the Civil Engineering Research Institute for Cold Regions. The tide records used in this study were provided by the Hokkaido Development Bureau.

\section{References}

Fujima K., Dozono R., Shigemura T. (2000) Generation and Propagation of tsunami accompanying edge waves on a uniform sloping shelf, Coastal Engineering Journal, 42, pp. 211-236.

González F. I., Satake K., Boss E. F., Mofjeld H. O. (1995) Edge wave and non-trapped modes of the 25 April 1992 Cape Mendocino Tsunami, PAGEOPH, 144, pp. 409-426.

Imai K., Satake K., Furumura T. (2009) Tsunami duration on the sounth coast of Shikoku from large earthquakes along the Nankai trough, J. Japan Soc. Civil Eng., Ser. B2 (Coastal Eng.), 65, pp. 281-285 (in Japanese).

Kawata Y., Okumura Y., Koshimura S., Fujima K., Nagai T. (2004) Study on the improvement of tsunami warning system considering generation of edge wave, Annu. J. Coastal Eng., 51, pp. 261-265 (in Japanese).

Kim J and Moin P 1985, Application of a fractional-step method to incompressible Navier-Stokes equations, J. Comp. Phys. 59, 308-323.

Lynett P. J., Wu T.-R., Liu L.-F. (2002) Modeling wave runup with depth-integrated equations, Coastal Engineering, 46, pp. 89-107.

MacNeice P., Olson, K.M., Mobarry, C., Fainchtein, R., Packer, C. (2000). PARAMESH: A parallel adaptive mesh refinement community toolkit, Comp. Phys. Comm., 126, pp. 330-354.

Mei C. C. (1983) The Applied Dynamics of Ocean Surface Waves, John Wiley and Sons.

Mori, N., Takahashi, T. and The 2011 Tohoku Earthquake Tsunami Joint Survey Group (2012 forthcoming). Nationwide Post Event Survey and Analysis of the 2011 Tohoku Earthquake Tsunami, Coastal Engineering Journal, 54(1), In press.

Pancheshnyi S., Segur, P., Capeillere, J., Bourdon, A. (2008). Numerical simulation of filamentary discharges with parallel adaptive mesh refinement, J. Comp. Phys., 227, pp. 6574-6590.

Watanabe, Y., Saeki, H. \& Hosking, R. J. (2005). Three-dimensional vortex structures under breaking waves. J. Fluid Mech., 545, pp. 291-328.

Watanabe, Y., Saruwatari, A. \& Ingram, D. M., 2008. Free-surface flows under impacting droplets. J. Comp. Phys., vol. 227, pp. 2344-2365.

Watanabe Y., Mitobe Y., Niida Y. and Yamada T. (2011). Application of Adaptive Mesh Refinement to Tsunami Computation, Proc. 21st Int. Offshore and Polar Eng. Conf. pp. 218-223. 